\title{
Modelling the delay between pharmacokinetics and EEG effects of morphine in rats: binding kinetic versus effect compartment models
}

\author{
Wilhelmus E. A. de Witte ${ }^{1}$. Vivi Rottschäfer ${ }^{2} \cdot$ Meindert Danhof $^{1} \cdot$ Piet H. van der Graaf ${ }^{1,3} \cdot$ Lambertus A. Peletier $^{2}$. \\ Elizabeth C. M. de Lange ${ }^{1}$
}

Received: 9 August 2017 / Accepted: 2 May 2018/Published online: 18 May 2018

(c) The Author(s) 2018

\begin{abstract}
Drug-target binding kinetics (as determined by association and dissociation rate constants, $k_{o n}$ and $k_{o f f}$ ) can be an important determinant of the kinetics of drug action. However, the effect compartment model is used most frequently instead of a target binding model to describe hysteresis. Here we investigate when the drug-target binding model should be used in lieu of the effect compartment model. The utility of the effect compartment (EC), the target binding kinetics (TB) and the combined effect compartment-target binding kinetics (EC-TB) model were tested on either plasma $\left(\mathrm{EC}_{\mathrm{PL}}, \mathrm{TB}_{\mathrm{PL}}\right.$ and $\mathrm{EC}-$ $\left.\mathrm{TB}_{\mathrm{PL}}\right)$ or brain extracellular fluid (ECF) $\left(\mathrm{EC}_{\mathrm{ECF}}, \mathrm{TB}_{\mathrm{ECF}}\right.$ and $\left.\mathrm{EC}-\mathrm{TB}_{\mathrm{ECF}}\right)$ morphine concentrations and $\mathrm{EEG}$ amplitude in rats. It was also analyzed when a significant shift in the time to maximal target occupancy ( $\left.\operatorname{Tmax}_{\mathrm{TO}}\right)$ with increasing dose, the discriminating feature between the TB and EC model, occurs in the TB model. All TB models assumed a linear relationship between target occupancy and drug effect on the EEG amplitude. All three model types performed similarly in describing the morphine pharmacodynamics data, although the EC model provided the best statistical result. The analysis of the shift in $\operatorname{Tmax}_{\mathrm{TO}}\left(\Delta \operatorname{Tmax}_{\mathrm{TO}}\right)$ as a result of increasing dose revealed that $\Delta \mathrm{Tmax}_{\mathrm{TO}}$ is decreasing towards zero if the $k_{\text {off }}$ is much smaller than the elimination rate constant or if the target concentration is larger than the initial morphine concentration. The results for the morphine PKPD modelling and the analysis of $\Delta \mathrm{Tmax}_{\mathrm{TO}}$ indicate that the EC and TB models do not necessarily lead to different drug effect versus time curves for different doses if a delay between drug concentrations and drug effect (hysteresis) is described. Drawing mechanistic conclusions from successfully fitting one of these two models should therefore be avoided. Since the TB model can be informed by in vitro measurements of $k_{\text {on }}$ and $k_{\text {off }}$, a target binding model should be considered more often for mechanistic modelling purposes.
\end{abstract}

Keywords Drug-target binding kinetics · Effect compartment model · PKPD modelling · Hysteresis · Morphine

$\begin{array}{ll}\text { Abbreviations } \\ \text { AIC } & \text { Akaike information criterion } \\ \text { CNS } & \text { Central nervous system } \\ \text { CV } & \text { Coefficient of variation }\end{array}$

Electronic supplementary material The online version of this article (https://doi.org/10.1007/s10928-018-9593-x) contains supplementary material, which is available to authorized users.

Elizabeth C. M. de Lange

ecmdelange@1acdr.leidenuniv.nl

1 Division of Pharmacology, Leiden Academic Centre for Drug Research, Leiden University, 2333 CC Leiden, The Netherlands

2 Mathematical Institute, Leiden University, 2333 CA Leiden, The Netherlands

3 Certara Quantitative Systems Pharmacology, Canterbury Innovation Centre, Canterbury CT2 7FG, UK

$\begin{array}{ll}\text { DE } & \text { Direct effect } \\ \text { ECF } & \text { Extracellular fluid } \\ \text { EC } & \text { Effect compartment } \\ \text { IE } & \text { Indirect effect } \\ \text { GOF } & \text { Goodness of fit } \\ \text { IIV } & \text { Inter-individual variability } \\ \text { OFV } & \text { Objective function value } \\ \text { Pgp } & \text { P-glycoprotein } \\ \text { PKPD } & \text { Pharmacokinetic-pharmacodynamic } \\ \text { TB } & \text { Target binding } \\ \text { Tmax } & \text { Time between dosing and maximal drug effect } \\ \text { Tmax } & \text { Time between dosing and maximal target } \\ & \text { occupancy } \\ \text { Tmax }_{\mathrm{TO}} & \text { Tmax } \\ & {\text { higher } \text { of the lower dose }- \text { Tmax }_{\mathrm{TO}} \text { of the }} \\ \text { VPC } & \text { Visual predictive check }\end{array}$




\section{Introduction}

Drug-target binding kinetics is an important criterion in the selection of drug candidates, as it can be a determinant of the time course and the selectivity of drug effect [1-4].

However, the in vivo time course of drug action is influenced by multiple factors including plasma pharmacokinetics, target site distribution, target binding kinetics, competition with endogenous ligands, turnover of the target, signal transduction kinetics and the kinetics of homeostatic feedback. As a consequence, the influence of binding kinetics on drug action can only be understood in conjunction with these kinetic processes and its relevance is still not fully understood and subject to an ongoing debate $[3,5-8]$.

One of the arguments against an important role of binding kinetics for in vivo drug action is that binding kinetics are most often not required to get a good fitting PKPD model for small molecules. However, numerous examples are available were binding kinetic models have been successfully applied, and binding kinetics are routinely incorporated in models for biologics and PET data [9-17]. The sparsity of target binding PKPD models for small molecules can be explained by the relatively fast binding kinetics of many drugs currently on the market, compared to their pharmacokinetics [3]. In addition, when a delay between drug concentrations and effect is observed, this delay is often described by an effect compartment or indirect response model $[18,19]$.

Here we study the difference between the effect compartment (EC) model, the target binding (TB) model, the direct effect (DE) and the indirect effect (IE) model, which are described below. The EC model describes the delay between pharmacokinetics (PK) and pharmacodynamics (PD) by including first order distribution of the drug into and out of a hypothetical target-site (biophase) compartment, which drives the pharmacodynamics [20]. The indirect effect (IE) model describes the delay between pharmacokinetics and pharmacodynamics by the zero order synthesis and first order degradation of an effector molecule which represents the pharmacodynamics [21]. The target binding (TB) model describes the delay between pharmacokinetics and pharmacodynamics by the second order drug-target association and first order dissociation of the drug-target complex [22-24]. The DE model describes no delay between the pharmacokinetics and pharmacodynamics and links the drug concentration directly to the effect measurements. All of these models can account for saturation of the PK-PD relationship (i.e. increasing drug concentrations do not increase the drug effect beyond a certain concentration), but this saturation can occur at different steps in the process between the drug concentration and the drug effect. For the EC model, the relationship between drug concentrations in the effect compartment and the effect can be saturable. For the IE model, both the relationship between the drug concentration and the synthesis or degradation rate of the effector molecule can be saturable. For the TB model, the relationship between the drug concentration and the target occupancy is saturable and the relationship between target occupancy and effect can be saturable. For the DE model, the relationship between the drug concentration and the drug effect can be saturable.

These models thus result in a zero, first and second order formation of the the pharmacodynamics in the EC, TB and IE model, respectively. This results in different dose dependencies of the time to the maximal effect $\left(\operatorname{Tmax}_{\mathrm{PD}}\right)$. As a current paradigm, the shift in $\operatorname{Tmax}_{\mathrm{PD}}\left(\Delta \mathrm{Tmax} \operatorname{mD}_{\mathrm{PD}}\right)$ in a PKPD dataset as a consequence of a change in the dose identifies the appropriate PKPD model to describe the data: with increasing dose, the $\operatorname{Tmax}_{\mathrm{PD}}$ can increase for the indirect response model, decrease for the TB model and is constant for the EC model [25-27].

However, in contrast to common belief, the indirect response model does not always result in an increasing $\operatorname{Tmax}_{\mathrm{PD}}$ with increasing doses but can also give rise to a decreasing $\operatorname{Tmax}_{\mathrm{PD}}$ with increasing doses, as shown by Peletier et al. [28]. If the relationship between target occupancy and effect is not delayed and monodirectional (i.e. an increase in target occupancy never results in a decrease in effect and vice versa), the $\operatorname{Tmax}_{\mathrm{PD}}$ coincides with the time to the maximal target occupancy $\left(\operatorname{Tmax}_{\mathrm{TO}}\right)$. To start with this most simple situation, we focus in this paper only on the Tmax ${ }_{\mathrm{TO}}$. A comprehensive analysis of the conditions for which a shift in $\operatorname{Tmax}_{\mathrm{TO}}$ for changing doses occurs in a TB model is currently not available. It might be that EC models have been used while TB models could have been applied equally well to describe the data in previous PKPD studies.

One example in which performance of $\mathrm{TB}$ and $\mathrm{EC}$ models has been investigated indicates comparable performance in describing the data of eight calcium channel blockers, but this study used only one dose level for all drugs [14] and therefore cannot be used to validate the relationship between dose and $\Delta \mathrm{Tmax}_{\mathrm{PD}}$. An additional complexity in choosing the most appropriate PKPD model to describe PKPD data is that, for most drugs, factors as target site distribution, drug-target binding and turnover of signaling molecules occur in parallel. It is not always needed to incorporate all these factors in the PKPD model, as only the rate limiting mechanism is required for a proper model fit that describes the observed data. However, leaving out such factors will never lead to understanding of the individual contributions and the interplay between these factors. Combined EC-TB models [13, 29, 30] as 
well as combined IE-TB models [10] have been applied successfully to discriminate between the contributions of separate factors. However, this discrimination is not always possible if one of the factors is relatively fast and does not contribute significantly to the delay between pharmacokinetics and pharmacodynamics [31-33]. In short, the relevance of drug-target binding kinetics cannot be excluded if one of the other models is successfully fitted to a dataset, and there is a need to generate more insight into the difference between the TB model and the EC model.

The aim of the current study is to investigate if the TB and EC model can give similar drug effect versus time curves and under what conditions this will occur. In this study, a historical PKPD dataset for morphine was used [34] to compare the goodness of fit for the TB model with the EC model and the combined EC-TB model in describing the time course of the EEG effect following administration of three different doses of morphine (4, 10 and $40 \mathrm{mg} / \mathrm{kg}$ ). Both plasma and brain extracellular fluid (ECF) drug concentrations were measured and tested in this study to be connected to the pharmacodynamics via an EC, TB or EC-TB model. Subsequently, a more general insight in the shift of $\operatorname{Tmax}_{\mathrm{TO}}(\Delta \mathrm{Tmax}$ то) for different dose levels in the drug-target binding model is obtained to identify for what parameter values the TB model can be discriminated from the EC model based on the $\Delta \mathrm{Tmax}_{\mathrm{TO}}$. To that end, comprehensive simulations and mathematical model analysis was performed for a wide range of drugtarget association and dissociation rate constants, for various plasma elimination rate constants, target concentrations, and dose levels.

\section{Methods}

\section{Pharmacokinetic and pharmacodynamic (PKPD) data of morphine in rats}

All pharmacokinetics and pharmacodynamics data used in this study were obtained from the experiments described earlier [35]. In short: Morphine was intravenously administered to Male Wistar rats, during a 10-min infusion, in 4 different dose groups: $0,4,10$ or $40 \mathrm{mg} / \mathrm{kg}$ with $5,29,11$ and 14 animals, respectively. The P-glycoprotein (Pgp) inhibitor GF120918 or vehicle was given as a continuous infusion. In the group of 29 animals that received $4 \mathrm{mg} / \mathrm{kg}$ morphine, 9 animals received GF120918, the other 20 animals received the vehicle. Furthermore, while plasma concentrations were measured in all animals, brain ECF concentrations were measured with microdialysis in 29 animals, of which 15 received $4 \mathrm{mg} / \mathrm{kg}, 0$ received $10 \mathrm{mg} /$ $\mathrm{kg}, 9$ received $40 \mathrm{mg} / \mathrm{kg}$ and 5 received $0 \mathrm{mg} / \mathrm{kg}$ morphine, see also Table 1.
For the modelling data set, all data entries without time recordings, without concentration data or with concentration data equal to 0 were removed from the dataset. The lower limit of quantification for morphine in plasma samples was $88 \mathrm{nM}$ and $1.75 \mathrm{nM}$ for morphine in ECF samples. The pharmacodynamics of morphine was measured as the amplitude in the $\delta$ frequency range $(0.5-4.5 \mathrm{~Hz})$ of the EEG and recorded every minute. The EEG data were further averaged for every 3-min interval to reduce the noise and decrease the model fitting time.

\section{General model fitting methods}

Data fitting was based on minimization of the objective function value $(\mathrm{OFV}=-2 * \log$ likelihood $)$ as implemented in NONMEM 7.3 [36]. Simulations and visualisations were performed in RStudio version 3.4.0. To account for the number of parameters for the comparison of non-nested models, the Akaike Information Criterion (AIC) was calculated by adding two times the number of estimated parameters to the OFV [37]. Variability in the data was described by IIV (Inter Individual Variability: variability in parameter values between animals) and a residual error term. IIV was implemented assuming a lognormal distribution according to Eq. 1:

$P_{i}=P_{p o p} * e^{\eta_{i}}$

In which $P_{i}$ is the individual parameter value, $P_{p o p}$ is the typical parameter value in the population and $\eta_{i}$ is normally distributed around a mean of zero with variance $\omega^{2}$ according to Eq. 2:

$\eta_{i} \sim N\left(0, \omega^{2}\right)$

The remaining variation between the data and the model predictions are incorporated as residual error for which both a proportional (Eq. 3) and a combined proportional and additive (Eq. 4) error model were tested.

$o b s_{i j}=\operatorname{pred}_{i j} *\left(1+\varepsilon_{\text {prop }, i j}\right)$

obs $_{i j}=\operatorname{pred}_{i j} *\left(1+\varepsilon_{\text {prop }, i j}\right)+\varepsilon_{a d d, i j}$

In these equations, $o b s_{i j}$ is the observation, $\operatorname{pred}_{i j}$ is the model prediction, $\varepsilon_{p r o p, i j}$ is the proportional error and $\varepsilon_{a d d, i j}$ is the additive error for individual $i$ at time point $j$. Both $\varepsilon_{p r o p, i j}$ and $\varepsilon_{a d d, i j}$ are normally distributed around a mean of zero with variance $\sigma^{2}$ according to Eqs. 5 and 6:

$\varepsilon_{\text {prop }, i j} \sim N\left(0, \sigma^{2}\right.$ prop $)$

$\varepsilon_{a d d, i j} \sim N\left(0, \sigma^{2} a d d\right)$. 
Table 1 Overview of treatment groups and data collection

\begin{tabular}{llcccc}
\hline Morphine dose & Pgp inhibitor & Plasma pharmacokinetics data & ECF pharmacokinetics data & EEG data & Dosed animals \\
\hline $0 \mathrm{mg} / \mathrm{kg}$ & - & 0 & 5 & 5 & 5 \\
$4 \mathrm{mg} / \mathrm{kg}$ & - & 20 & 7 & 16 & 20 \\
$4 \mathrm{mg} / \mathrm{kg}$ & + & 9 & 8 & 9 & 9 \\
$10 \mathrm{mg} / \mathrm{kg}$ & - & 11 & 9 & 11 & 11 \\
$40 \mathrm{mg} / \mathrm{kg}$ & - & 14 & 29 & 54 & 13 \\
Total & 54 & & 9 & 59 \\
\hline
\end{tabular}

\section{Morphine plasma pharmacokinetics modelling}

One-compartment, two-compartment and three-compartment models were fitted to the plasma pharmacokinetics data, with both proportional and additive plus proportional error models, and with IIV on the various parameters. The differential equations and model scheme are given in Supplement S1. The best fits (based on AICs) of each structural model were compared for their Goodness Of Fits (GOFs) and AICs. Since the purpose of the plasma pharmacokinetics modelling was to get the best possible input for the pharmacodynamics modelling, GOF was assessed by the AIC and by individual fits. Over- or underestimation of IIV and population parameter estimates and high uncertainties in population parameter estimates were not regarded as problematic, since only the right individual parameter estimates were required for pharmacodynamics modeling.

\section{Morphine brain ECF pharmacokinetics Modelling}

The individual parameter estimates that were estimated to describe the plasma pharmacokinetics were used as fixed parameters to describe the plasma pharmacokinetics profile as input for the brain ECF concentrations. To describe the ECF concentrations, we thus assumed that the distribution of the drug into and out of the ECF did not lead to a change in plasma concentrations. The differential equations and model scheme are given in Supplement S1. The best fits, based on the AICs, of each structural model were compared for their GOFs and AICs. Since the purpose of the brain ECF pharmacokinetics modelling was to get the best possible input for the pharmacodynamics modelling, GOF was assessed by the AIC and by individual fits. Over- or underestimation of IIV and population parameter estimates and high uncertainties in population parameter estimates were not regarded as problematic, since only the right individual parameter estimates were required for pharmacodynamics modeling.

\section{EEG pharmacodynamics modelling}

To maximize the identifiability of the pharmacodynamics model parameters, all pharmacokinetic parameters were used as fixed parameters to describe the plasma and brain ECF concentrations as input for all the described pharmacodynamics models to describe EEG effects [38]. The different type of models that were tested are outlined in Table 2. The differential equations are given in Supplement S1. For each model, the most informative variations on the model structure are given in the results section.

To compare structural models that linked plasma or brain ECF concentrations directly to the PD, the models that used plasma pharmacokinetics were fitted to the reduced dataset that only contained animals with plasma PK, brain ECF and EEG measurements. Model comparison was based on the AIC, visual inspection of the GOF and a VPC (Visual Predictive Check) to check if the IIV was captured appropriately.

\section{Drug-target binding model simulations}

Simulations with a one-compartment binding model with IV administration were performed for a wide range of $k_{\text {on }}$

Table 2 Overview of the different model types, the data that were used and the model numbers as used in this manuscript

\begin{tabular}{lll}
\hline Model type & Concentrations linked to effect & Model number \\
\hline EC & Plasma & $\mathrm{EC}_{\mathrm{PL}} 1-\mathrm{EC}_{\mathrm{PL}} 4$ \\
$\mathrm{EC}$ & $\mathrm{ECF}$ & $\mathrm{EC}_{\mathrm{ECF}} 1$ \\
$\mathrm{~TB}$ & Plasma & $\mathrm{TB}_{\mathrm{PL}} 1-\mathrm{TB}_{\mathrm{PL}} 5$ \\
$\mathrm{~TB}$ & $\mathrm{ECF}$ & $\mathrm{TB}_{\mathrm{ECF}} 1$ \\
$\mathrm{EC}-\mathrm{TB}$ & $\mathrm{Plasma}$ & $\mathrm{ECTB}_{\mathrm{PL}} 1-\mathrm{ECTB}_{\mathrm{PL}} 5$ \\
$\mathrm{IE}$ & $\mathrm{ECF}$ & $\mathrm{IE}_{\mathrm{ECF}} 1$ \\
$\mathrm{DE}$ & $\mathrm{ECF}$ & $\mathrm{DE}_{\mathrm{ECF}} 1$ \\
\hline
\end{tabular}

$E C$ effect compartment, $T B$ target binding, $E C-T B$ effect compartment-target binding, $I E$ indirect effect, $D E$ direct effect, $E C F$ brain extracellular fluid 
Table 3 Overview of the different simulation scenarios

\begin{tabular}{llclc}
\hline Simulation \# & $k_{\text {el }}(1 / \mathrm{h})$ & $R_{\text {tot }}(\mathrm{nM})$ & $C_{0}$ low $\left(* K_{D}\right)$ & $\mathrm{C}_{0}$ high $\left(* K_{D}\right)$ \\
\hline 1 & 0.03 & 0.1 & 0.5 & 5 \\
2 & 0.03 & 0.1 & 5 & 50 \\
3 & 0.03 & 10 & 0.5 & 5 \\
4 & 0.3 & 0.1 & 0.5 & 5
\end{tabular}

For each simulation, $k_{\text {on }}$ and $k_{\text {off }}$ varied between $10^{-3}$ and $10^{3} / \mathrm{nM} / \mathrm{h}$ and between $10^{-3}$ and $10^{3} \mathrm{~h}^{-1}$, respectively

and $k_{\text {off }}$ values and for a variety of elimination rate constants, target concentrations and drug dose levels (Table 3). The $\operatorname{Tmax}_{\mathrm{TO}}$ was compared for two different doses to determine the influence of the drug dose on the Tmax ${ }_{\mathrm{TO}}$. The $\Delta \operatorname{Tmax}_{\mathrm{TO}}$ values were calculated by subtracting the $\mathrm{Tmax}_{\mathrm{TO}}$ of the highest dose from the Tmax $\mathrm{T}_{\mathrm{TO}}$ of the lowest dose and $\Delta \operatorname{Tmax}_{\mathrm{TO}}$ was plotted against $k_{\text {on }}$ and $k_{\text {off. }}$.

\section{Results}

\section{Morphine pharmacokinetics modelling}

Modelling of morphine pharmacokinetic data in plasma and brain ECF as described in Supplement S1 identified very similar model structures as previously described for pharmacokinetic modelling of the same dataset by Groenendaal and coworkers [35]. In short, the plasma concentrations were described by a three-compartment model and the ECF concentrations were described by passive distribution into and out of the brain combined with saturable active influx and first-order efflux.

\section{EEG pharmacodynamics modelling}

\section{$\mathrm{EC}_{\mathrm{PL}}$ model fitting}

EC and TB models have been applied to the morphine data to describe the relationship between the observed plasma concentrations and EEG amplitude and direct effect (DE), indirect effect (IE), EC and TB models have been applied to brain ECF and EEG amplitude data. The differential equations for these models are given in Supplement S1. Firstly, the originally published $\mathrm{EC}_{\mathrm{PL}}$ model structure was optimized by adding a slope-parameter, which describes the linear decline of EEG amplitude over time during the experiment independently of the drug effect, and by including IIV on the baseline EEG amplitude only. For this model, a transit compartment was required between the plasma and the effect compartment for the best description of the data [34]. An overview of the different variations on this basic model structure is given in Table 4 . The structure of all $\mathrm{EC}_{\mathrm{PL}}$ is identical and is depicted in Fig. 1. Based on the AIC, the parameter estimates and the GOF, model $\mathrm{EC}_{\mathrm{PL}} 1$ was chosen as the best parameterization for the effect compartment model in Fig. 1.

\section{$\mathrm{TB}_{\mathrm{PL}}$ model fitting}

The $\mathrm{TB}_{\mathrm{PL}}$ model was applied to describe target binding from plasma, all $\mathrm{TB}_{\mathrm{PL}}$ models in Table 5 shared the same structure as represented in Fig. 2. The parameter estimation results are given in Table 5. Since the target concentration is of influence only if it is similar to the drug concentration (which is mostly above $100 \mathrm{nM}$ in plasma and in brain ECF, as shown in Supplement S1), the target concentration could not be estimated in this model and was fixed to an arbitrary low value of $1 \mathrm{nM}$ in the model estimations. This low target concentration prevents the influence of the target concentration on the EEG amplitude in the model. The influence of blocking Pgp has been incorporated by estimating separate parameter values with and without the presence of Pgp blocker. While the influence of blocking Pgp on the $k_{\text {off }}$ or $K_{D}$ is mechanistically not plausible, the improved model fits for the models which incorporate these influences might indicate that the estimated $k_{\text {off }}$ and $K_{D}$ values refer to apparent values which include not only the molecular properties. The target occupancy is linearly related to the EEG amplitude in model $\mathrm{TB}_{\mathrm{PL}} 1-\mathrm{TB}_{\mathrm{PL}} 5$, as nonlinear relationships could not be identified accurately in this study. On basis of the objective function values, model $\mathrm{TB}_{\mathrm{PL}} 4$ was selected as the best drug-target binding model. It should be noted that the AIC of model $\mathrm{TB}_{\mathrm{PL}} 4$ is 338 points higher than model $\mathrm{EC}_{\mathrm{PL}} 1$, which means that model $\mathrm{EC}_{\mathrm{PL}} 1$ performs better in fitting the data. All $\mathrm{TB}_{\mathrm{PL}}$ models have one compartment less than the transit-EC models $\mathrm{EC}_{\mathrm{PL}} 1-\mathrm{EC}_{\mathrm{PL}} 4$. Therefore, the combined $\mathrm{EC}-\mathrm{TB}_{\mathrm{PL}}$ models $\mathrm{EC}-\mathrm{TB}_{\mathrm{PL}} 1$ to $\mathrm{EC}-\mathrm{TB}_{\mathrm{PL}} 5$ were developed.

\section{EC-TB $B_{P L}$ model fitting}

The EC-TB $\mathrm{PL}_{\mathrm{PL}}$ model structure that was tested to describe the EEG data is shown in Fig. 3. This model enables the comparison between the target binding and effect compartment mechanism, as both models have an additional compartment between the plasma compartment and the compartment that is linked directly to the effect. The parameter values, OFVs and AICs are given in Table 6. Parameter values and objective function values of the tested $\mathrm{EC}-\mathrm{TB}_{\mathrm{PL}}$ models describing the EEG data, based on plasma concentrations. $\mathrm{CV}$ denotes the coefficient of variation as percentage. OFV denotes the Objective Function Value, AIC denotes the Akaike Information Criterion. $\omega^{2}$ and $\sigma^{2}$ denote the variances of the exponential 
Table 4 Parameter values and objective function values of the tested EC models describing the EEG data, based on plasma concentrations

\begin{tabular}{|c|c|c|c|c|c|}
\hline & Parameter definition & $\begin{array}{l}\mathrm{EC}_{\mathrm{PL}} 1 \text { selected } \\
\text { model }\end{array}$ & $\begin{array}{l}\mathrm{EC}_{\mathrm{PL}} 2 \text { no } \\
\text { slope }\end{array}$ & $\begin{array}{l}\mathrm{EC}_{\mathrm{PL}} 3 \\
k_{1 e}=k_{e o}\end{array}$ & $\begin{array}{l}\mathrm{EC}_{\mathrm{PL}} 4 \text { no Pgp } \\
\text { effect }\end{array}$ \\
\hline OFV & & $44,748.0$ & $45,084.2$ & $44,853.3$ & $44,868.4$ \\
\hline AIC & & $44,770.0$ & $45,104.2$ & $44,871.3$ & $44,886.4$ \\
\hline Parameter & Parameter definition & Value $(\% \mathrm{CV})$ & $\begin{array}{l}\text { Value } \\
(\% \mathrm{CV})\end{array}$ & Value (\%CV) & Value (\%CV) \\
\hline$k_{1 e}(/ \min )$ & Distribution to transit compartment & $0.0393(18)$ & $0.0432(10)$ & $0.0403(10)$ & $0.0375(8)$ \\
\hline$k_{e o}(/ \min )$ & Distribution from effect compartment & $0.0382(14)$ & $0.0458(9)$ & - & $0.0375(8)$ \\
\hline $\begin{array}{l}k_{1 e^{-P g p}(/} \\
\min )\end{array}$ & Distribution to transit with Pgp blocker & $0.0565(44)$ & $0.0661(38)$ & $0.0295(18)$ & - \\
\hline $\begin{array}{l}k_{e o}-P g p(/ \\
\min )\end{array}$ & Distribution from effect with Pgp blocker & $0.016(46)$ & $0.0203(20)$ & - & - \\
\hline$E_{0}(\mu \mathrm{V})$ & Baseline EEG amplitude & $45.1(4)$ & $42.2(4)$ & $45.8(4)$ & $45.9(4)$ \\
\hline$E_{\max }(\mu \mathrm{V})$ & Maximal increase in EEG amplitude & $27.9(23)$ & $25.3(16)$ & $26.1(18)$ & $27.0(18)$ \\
\hline$E C_{50}(\mathrm{nM})$ & $\begin{array}{l}\text { concentration giving half-maximal increase in EEG } \\
\text { amplitude }\end{array}$ & $1270(52)$ & $1220(31)$ & $912(37)$ & $1000(37)$ \\
\hline$N_{H}$ & Hill factor & $1.44(43)$ & $2.02(27)$ & $1.46(36)$ & $1.37(33)$ \\
\hline $\begin{array}{l}\text { slope }(\mu \mathrm{V} / \\
\min )\end{array}$ & Increase in baseline EEG over time & $-0.024(22)$ & 0 FIX & $\begin{array}{l}-0.0263 \\
(15)\end{array}$ & $-0.0267(15)$ \\
\hline$\omega^{2} E_{0}(\mu \mathrm{V})$ & IIV variance on $E_{0}$ & $0.111(20)$ & $0.125(19)$ & $0.115(20)$ & $0.116(20)$ \\
\hline$\sigma^{2}$ prop & Variance of proportional error & $0.0554(7)$ & $0.0584(7)$ & $0.0562(6)$ & $0.0564(6)$ \\
\hline
\end{tabular}

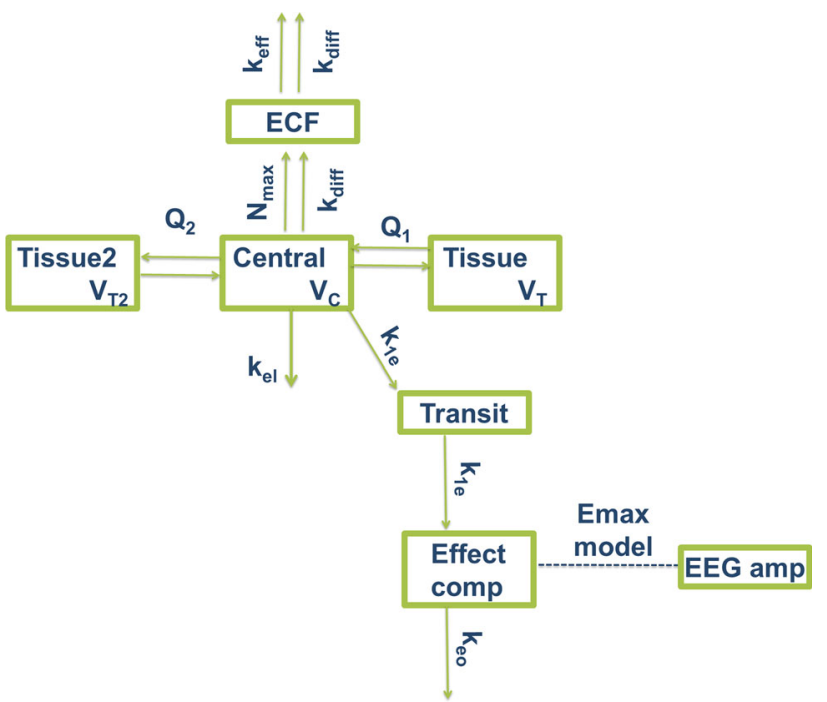

Fig. 1 Schematic representation of the $\mathrm{EC}_{\mathrm{PL}}$ model structure that was used to describe the morphine EEG amplitudes over time. $k_{i e}$, firstorder in- and outward distribution rate constant for the transit compartment. $k_{e o}$, first-order outward distribution rate constant from the effect compartment. The effect compartment concentrations were linked to the EEG amplitude by a sigmoidal Emax model. The distribution from plasma to the tissue compartments and the brain ECF compartment is described in Supplement S1. The arrows indicate morphine flows, the dotted line indicates a direct relationship

IIV distribution and the proportional error distribution, respectively. Model EC-TB $\mathrm{TL}_{\mathrm{PL}} 1$ was selected as best model on basis of the AIC, but this AIC is still 39 points higher than Model $\mathrm{EC}_{\mathrm{PL}} 1$. The uncertainty in the parameter estimate of the $K_{D}$ in the presence of the Pgp blocker $\left(K_{D^{-}}\right.$ $P g p$ ) is rather high with $93 \%$, but this was allowed to test the conclusion that none of the binding models $\left(\mathrm{TB}_{\mathrm{PL}} 1-\right.$ $\mathrm{TB}_{\mathrm{PL}} 5$ and $\mathrm{EC}-\mathrm{TB}_{\mathrm{PL}} 1$ to $\mathrm{EC}-\mathrm{TB}_{\mathrm{PL}} 5$ ) yielded lower AICs than the best effect compartment model $\left(\mathrm{EC}_{\mathrm{PL}} 1\right)$ in a conservative manner.

\section{$\mathrm{EC}_{\mathrm{ECF}}, \mathrm{TB}_{\mathrm{ECF}}, \mathrm{IE}_{\mathrm{ECF}}$ and $\mathrm{DE}_{\mathrm{ECF}}$ model fitting}

The last models that were fitted to the EEG data were based on the ECF concentrations instead of the plasma concentrations. Various model structures were tested, as shown in Fig. 4. To compare the model fits based on ECF concentrations $\left(\mathrm{EC}_{\mathrm{ECF}} 1, \mathrm{~TB}_{\mathrm{ECF}} 1, \mathrm{IE}_{\mathrm{ECF}} 1\right.$ and $\left.\mathrm{DE}_{\mathrm{ECF}} 1\right)$ with the model fits that were based on plasma concentrations $\left(\mathrm{EC}_{\mathrm{PL}}\right.$, $\mathrm{TB}_{\mathrm{PL}}$ and $\left.\mathrm{EC}-\mathrm{TB}_{\mathrm{PL}}\right)$, the best plasma model $\left(\mathrm{EC}_{\mathrm{PL}} 1\right)$ was fitted to the limited dataset that included only animals with ECF data. This model fit was compared to the ECF-based model fits on basis of their AICs, as shown in Table 7.

Of all the models that are described above, model $\mathrm{EC}_{\mathrm{PL}} 1$ has the lowest AIC. To evaluate its performance in more detail, the most relevant diagnostic plots are given in Figures S6-S10. These diagnostic plots indicate that the main trend of the data is captured, although the obtained fit is not optimal (which is especially clear from Figure S10). The small difference in AIC between the best combined EC-TB model $\left(\mathrm{EC}-\mathrm{TB}_{\mathrm{PL}} 1\right)$ and the best EC model 
Table 5 Parameter values and objective function values of the tested $\mathrm{TB}_{\mathrm{PL}}$ models describing the EEG data, based on plasma concentrations

\begin{tabular}{|c|c|c|c|c|c|c|}
\hline & Parameter definition & $\begin{array}{l}\mathrm{TB}_{\mathrm{PL}} 1 \text { no Pgp effect } \\
\text { slope }=0\end{array}$ & $\begin{array}{l}\mathrm{TB}_{\mathrm{PL}} 2 \text { no Pgp } \\
\text { effect }\end{array}$ & $\begin{array}{l}\mathrm{TB}_{\mathrm{PL}} 3 \text { Pgp on } \\
\mathrm{k}_{\text {off }}\end{array}$ & $\begin{array}{l}\mathrm{TB}_{\mathrm{PL}} 4 \text { selected } \\
\text { model }\end{array}$ & $\begin{array}{l}\mathrm{TB}_{\mathrm{PL}} 5 \\
\text { slope }=0\end{array}$ \\
\hline OFV & & $45,677.7$ & $45,170.1$ & $45,166.6$ & $45,092.1$ & $45,536.9$ \\
\hline AIC & & $45,689.7$ & $45,184.1$ & $45,182.6$ & $45,108.1$ & $45,550.9$ \\
\hline Parameter & Parameter definition & Value $(\% \mathrm{CV})$ & Value $(\% \mathrm{CV})$ & Value $(\% \mathrm{CV})$ & Value $(\% \mathrm{CV})$ & $\begin{array}{l}\text { Value } \\
(\% \mathrm{CV})\end{array}$ \\
\hline$k_{\text {off }}(/ \mathrm{min})$ & Dissociation rate constant & $0.017(8)$ & $0.0103(13)$ & $0.0109(17)$ & $0.009(26)$ & $0.0149(15)$ \\
\hline $\begin{array}{l}k_{\text {off }}-P g p(/ \\
\text { min })\end{array}$ & $\begin{array}{l}\text { Dissociation rate constant with } \\
\text { Pgp blocker }\end{array}$ & - & - & $0.0087(26)$ & - & - \\
\hline$K_{D}(\mathrm{nM})$ & Equilibrium constant & $1980(37)$ & $995(36)$ & $935(37)$ & $1570(59)$ & 3610 \\
\hline $\begin{array}{l}K_{D}-P g p \\
(\mathrm{nM})\end{array}$ & $\begin{array}{l}\text { Equilibrium constant with Pgp } \\
\text { blocker }\end{array}$ & & & & $381(88)$ & 715 \\
\hline$E_{0}(\mu \mathrm{V})$ & Baseline EEG amplitude & $42.4(4)$ & $45.9(4)$ & $45.8(4)$ & $45.4(4)$ & 42.2 \\
\hline$E_{\max }(\mu \mathrm{V})$ & $\begin{array}{l}\text { Maximal increase in EEG } \\
\text { amplitude }\end{array}$ & $32.2(14)$ & $29.3(13)$ & $28.9(13)$ & $32.9(20)$ & 38.9 \\
\hline$R_{t o t}(\mathrm{nM})$ & Target concentration & 1 FIX & 1 FIX & 1 FIX & 1 FIX & 1 FIX \\
\hline $\begin{array}{l}\text { slope }(\mu \mathrm{V} / \\
\text { min })\end{array}$ & $\begin{array}{l}\text { Increase in baseline EEG over } \\
\text { time }\end{array}$ & 0 FIX & $-0.0313(13)$ & $\begin{array}{l}-0.0315 \\
(12)\end{array}$ & $-0.0299(12)$ & 0 FIX \\
\hline$\omega^{2} E_{0}(\mu \mathrm{V})$ & IIV variance on $E_{0}$ & $0.135(18)$ & $0.117(20)$ & $0.117(20)$ & $0.113(19)$ & $0.13(17)$ \\
\hline$\sigma^{2}$ prop & Variance of proportional error & $0.0639(6)$ & $0.059(6)$ & $0.059(6)$ & $0.0584(6)$ & $0.0626(6)$ \\
\hline
\end{tabular}

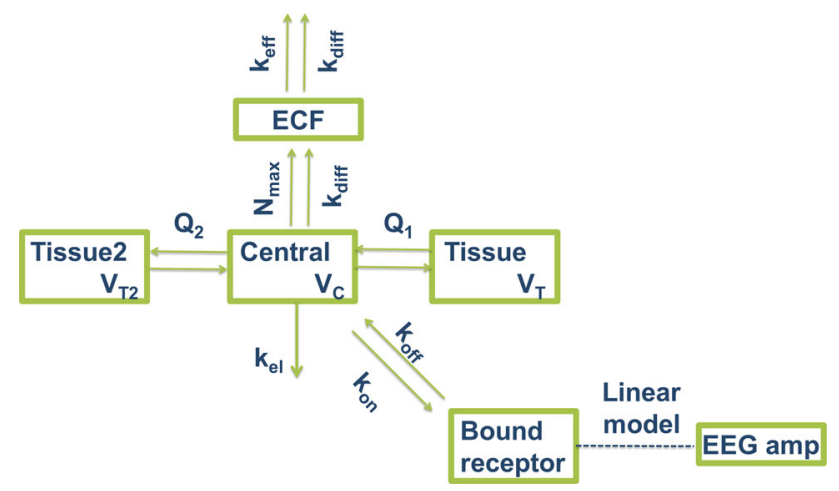

Fig. 2 Schematic representation of the $\mathrm{TB}_{\mathrm{PL}}$ model structure that was used to describe the morphine EEG amplitudes over time. $k_{o n}$ is the second-order drug-target association rate constant. $k_{\text {off }}$ is the firstorder drug-target dissociation rate constant. Target occupancy is linearly related to the EEG amplitude. The distribution from plasma to the tissue compartments and the brain ECF compartment is described in Supplement S1. The arrows indicate morphine flows, the dotted line indicates a direct relationship

$\left(\mathrm{EC}_{\mathrm{PL}} 1\right)$ is also reflected by very similar VPC results, as shown in Figure S11. Moreover, the best model with only binding from plasma $\left(\mathrm{TB}_{\mathrm{PL}} 4\right)$ also provided a similar VPC result (see Figure S12).

\section{Dose-dependency of $\operatorname{Tmax}_{\mathrm{TO}}$ in a $\mathrm{TB}_{\mathrm{PL}}$ model}

Simulations of drug-target binding in a $\mathrm{TB}_{\mathrm{PL}}$ model for the range of the most relevant binding kinetics demonstrated that the observable influence of dose on $\operatorname{Tmax}_{\mathrm{TO}}$, which discriminates the TB model from the EC model, is limited to a confined range of $k_{\text {on }}$ and $k_{\text {off }}$ combinations. As visualized in Fig. 5 , if the $k_{\text {off }}$ has a value around the elimination rate constant of $0.03 / \mathrm{h}, \Delta \mathrm{Tmax}_{\mathrm{TO}}$ is maximal. Also, the initial drug concentration $C O$ should not be above a specific threshold value which is approximately equal to the target concentration. The absolute $\Delta \operatorname{Tmax}_{\mathrm{TO}}$ for different doses (as shown in Fig. 5) will be most relevant for the identification of the dose-dependent $\Delta \operatorname{Tmax}_{\mathrm{TO}}$ in a PKPD modelling study. However, for the understanding of the underlying determinants of this shift in $\Delta \mathrm{Tmax}_{\mathrm{TO}}$, the ratio of the $\Delta \mathrm{Tmax}_{\mathrm{TO}}$ values belonging to the two doses should also be considered, as shown in Fig. 6. For example, if the two different $\operatorname{Tmax}_{\mathrm{TO}}$ values obtained from the two doses are 1 and $3 \mathrm{~min}$, their ratio is 3 , but the absolute difference is $2 \mathrm{~min}$. If the two $\operatorname{Tmax}_{\mathrm{TO}}$ values are 1 and $3 \mathrm{~h}$, their ratio is still 3 , but the difference is now $2 \mathrm{~h}$. In this latter case, the influence of the dose on the Tmax will be more easily identified. Representative example simulations that can help to understand the characteristics of Fig. 5 are provided in Supplement S2.

Interestingly, the relationship between the $\Delta \mathrm{Tmax}_{\mathrm{TO}}$, the elimination rate constant, the target concentration and the dose could be approximated mathematically for the upper region, the lower-left region and the lower-right region of Fig. 5 as presented in Supplement S3. From this analysis, it follows that for the upper half of Fig. 5, where the $k_{\text {off }}$ is much larger than the $k_{e l}$, Tmax $\operatorname{Tm}_{\mathrm{TO}}$ is always small, and a significant $\Delta \operatorname{Tmax}_{\mathrm{TO}}$ will thus not be observed. For 


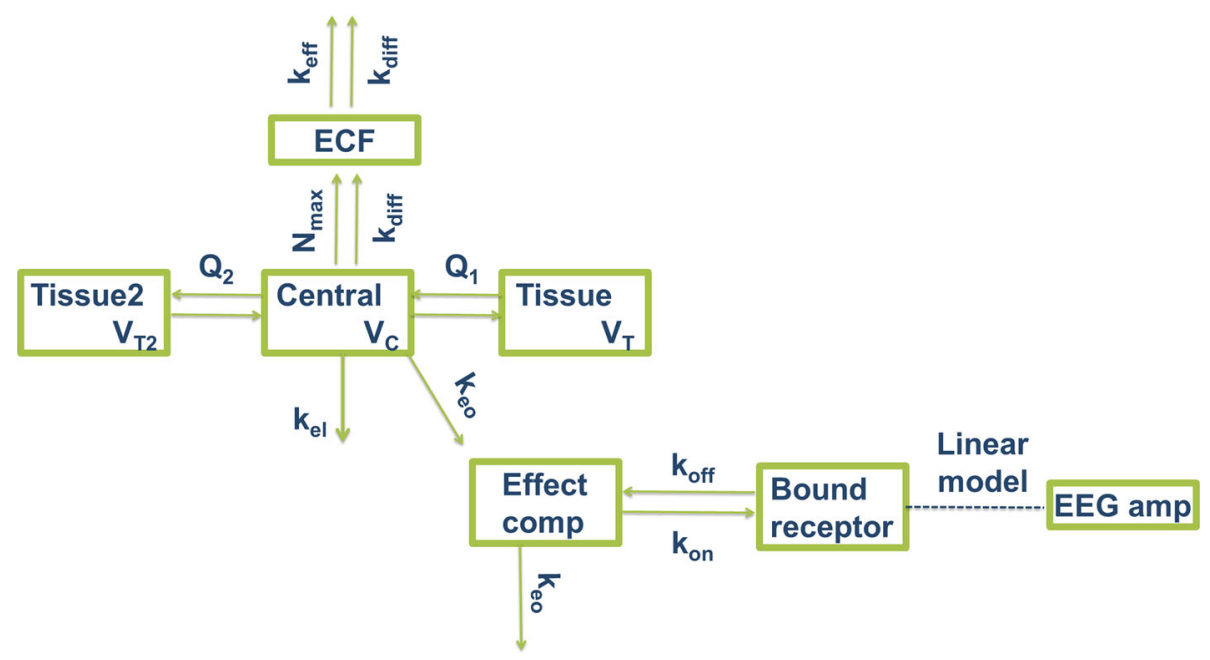

Fig. 3 Schematic representation of the $\mathrm{EC}-\mathrm{TB}_{\mathrm{PL}}$ model structure that was used to describe the morphine EEG amplitudes over time. $k_{o n}$ is the second-order drug-target association rate constant. $k_{\text {off }}$ is the firstorder drug-target dissociation rate constant. $k_{e o}$ is the first-order distribution rate constant into and out of the effect compartment.
Target occupancy is linearly related to the EEG amplitude. The distribution from plasma to the tissue compartments and the brain ECF compartment is described in Supplement S1. The arrows indicate morphine flows, the dotted line indicates a direct relationship

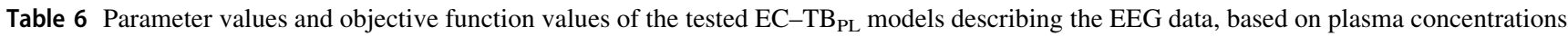

\begin{tabular}{|c|c|c|c|c|c|c|}
\hline & Parameter definition & $\begin{array}{l}\mathrm{EC}-\mathrm{TB}_{\mathrm{PL}} 1 \\
\text { selected model }\end{array}$ & $\begin{array}{l}\text { EC-TB }{ }_{P L} 2 \text { no } \\
\text { Pgp effect }\end{array}$ & $\begin{array}{l}\mathrm{EC}-\mathrm{TB}_{\mathrm{PL}} 3 \mathrm{Pgp} \\
\text { on } \mathrm{k}_{\mathrm{eo}}\end{array}$ & $\begin{array}{l}\mathrm{EC}-\mathrm{TB}_{\mathrm{PL}} 4 \\
\mathrm{k}_{\mathrm{off}}=1\end{array}$ & $\begin{array}{l}\mathrm{EC}-\mathrm{TB}_{\mathrm{PL}} 5 \\
\text { slope }=0\end{array}$ \\
\hline OFV & & $44,790.9$ & $44,880.3$ & $44,873.8$ & $45,008.2$ & $45,235.3$ \\
\hline AIC & & $44,808.9$ & $44,896.3$ & $44,891.8$ & $45,024.2$ & $45,251.3$ \\
\hline Parameter & Parameter definition & Value (\%CV) & Value (\%CV) & Value (\%CV) & $\begin{array}{l}\text { Value } \\
(\% \mathrm{CV})\end{array}$ & Value $(\% \mathrm{CV})$ \\
\hline$k_{\text {off }}(/ \mathrm{min})$ & Dissociation rate constant & $0.0275(14)$ & $0.0243(14)$ & $0.0247(14)$ & 1 FIX & $0.0400(9)$ \\
\hline$k_{e o}(/ \min )$ & $\begin{array}{l}\text { Distribution rate constant to effect } \\
\text { compartment }\end{array}$ & $0.0327(17)$ & $0.0365(12)$ & $0.0389(14)$ & $0.0162(28)$ & $0.036(13)$ \\
\hline $\begin{array}{l}k_{e o}-P g p(/ \\
\min )\end{array}$ & $\begin{array}{l}\text { Distribution to effect compartment } \\
\text { with Pgp blocker }\end{array}$ & - & - & $0.0265(31)$ & - & - \\
\hline$K_{D}(\mathrm{nM})$ & Equilibrium constant & $1520(34)$ & $1150(30)$ & $1110(30)$ & $2110(50)$ & $3150(36)$ \\
\hline $\begin{array}{l}K_{D}-P g p \\
(\mathrm{nM})\end{array}$ & $\begin{array}{l}\text { Equilibrium constant with Pgp } \\
\text { blocker }\end{array}$ & $296(93)$ & - & - & $385(78)$ & $594(47)$ \\
\hline$E_{0}(\mu \mathrm{V})$ & Baseline EEG amplitude & $45.0(4)$ & 45.7 (4) & $45.6(4)$ & $45.2(4)$ & $41.9(4)$ \\
\hline$E_{\max }(\mu \mathrm{V})$ & Maximal increase in EEG amplitude & $31.8(11)$ & $30.7(11)$ & $30.5(11)$ & $34.4(18)$ & $37.3(12)$ \\
\hline$R_{t o t}(\mathrm{nM})$ & Target concentration & 1 FIX & 1 FIX & 1 FIX & $1 \mathrm{FIX}$ & 1 FIX \\
\hline $\begin{array}{l}\text { slope }(\mu \mathrm{V} / \\
\text { min })\end{array}$ & Increase in baseline EEG over time & $-0.0276(15)$ & $-0.0296(13)$ & $-0.0296(13)$ & $\begin{array}{l}-0.0273 \\
(14)\end{array}$ & 0 FIX \\
\hline $\begin{array}{l}\omega^{2} E_{0} \\
(\mu \mathrm{V})\end{array}$ & IIV variance on $E_{0}$ & $0.111(20)$ & $0.116(20)$ & $0.116(20)$ & $0.111(19)$ & $0.129(18)$ \\
\hline$\sigma^{2}$ prop & Variance of proportional error & $0.057(7)$ & $0.0565(7)$ & $0.0565(7)$ & $0.0576(7)$ & $0.0597(7)$ \\
\hline
\end{tabular}

the lower and the lower-right part of Fig. 5, where the $k_{\text {off }}$ is much smaller than the $k_{e l}$, it is found that $\operatorname{Tmax}_{\mathrm{TO}}$ does not depend on the dose. More specifically, when the initial drug concentration is much lower than the target concentration (and $k_{\text {off }}$ is smaller than $k_{e l}$ ), the $\operatorname{Tmax}_{\mathrm{TO}}$ is merely determined by the $k_{e l}$. On the other hand, when the initial drug concentration is much larger than the target concentration (and $k_{\text {off }}$ is smaller than $k_{e l}$ ), the $\operatorname{Tmax}_{\mathrm{TO}}$ is given by a relation between $k_{\text {off }}$ and $k_{e l}$. This relationship between the $\Delta \mathrm{Tmax}_{\mathrm{TO}}$, the elimination rate constant, the target concentration and the dose is illustrated in Fig. 7. 

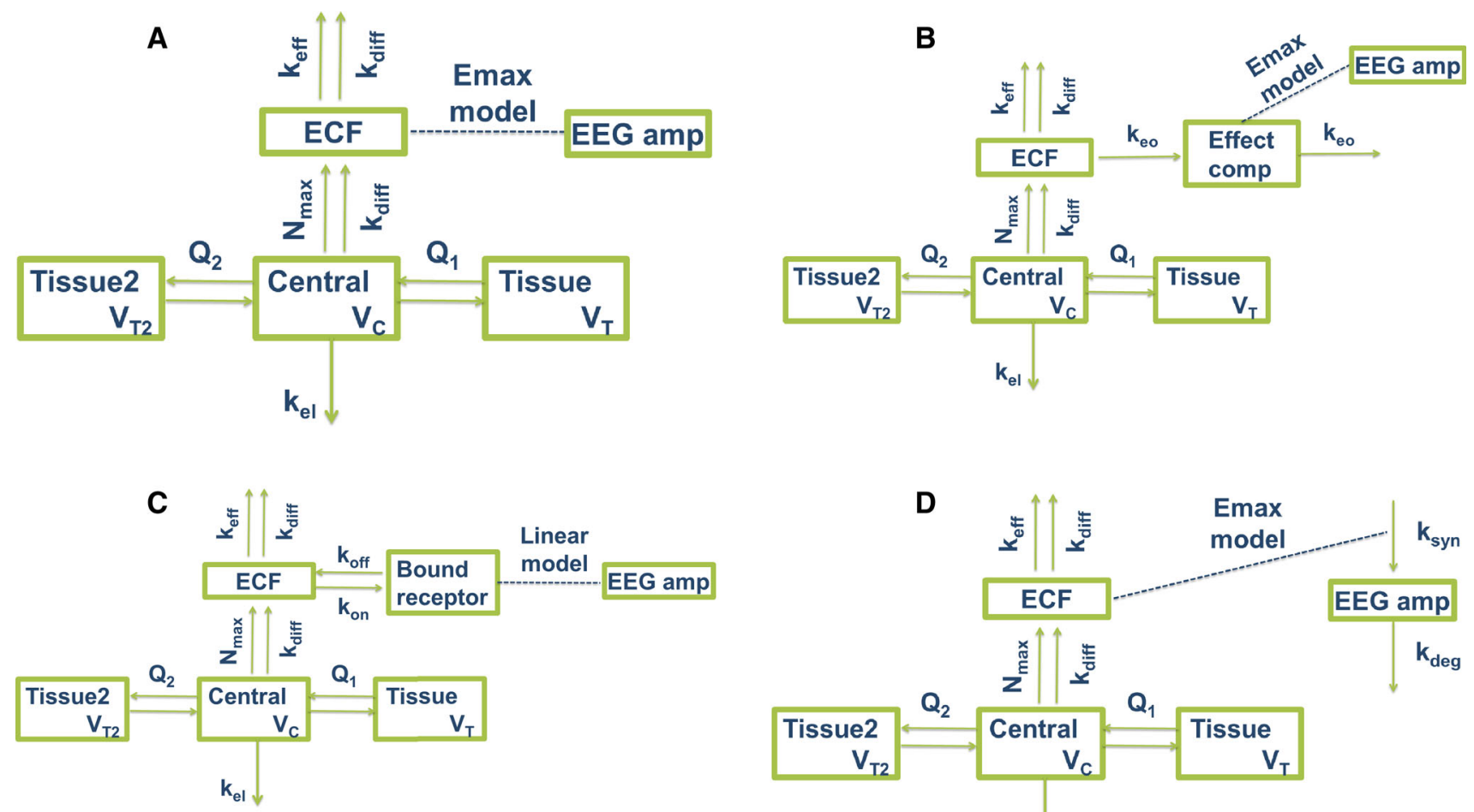

Fig. 4 Schematic representation of the $\mathrm{EC}_{\mathrm{ECF}}, \mathrm{TB}_{\mathrm{ECF}}, \mathrm{IE}_{\mathrm{ECF}}$ and $\mathrm{DE}_{\mathrm{ECF}}$ model structures that were used to describe the EEG data, based on brain ECF concentrations. The different structures represent $\mathbf{a}$ the $\mathrm{DE}_{\mathrm{ECF}}$ model, $\mathbf{b}$ the $\mathrm{EC}_{\mathrm{ECF}}$ model, $\mathbf{c}$ the $\mathrm{TB}_{\mathrm{ECF}}$ model and $\mathbf{d}$ the $\mathrm{IE}_{\mathrm{ECF}}$ model, with $k_{s y n}$ being the zero-order effect generation rate

\section{Discussion}

In this study, TB and EC models were compared to describe the delay between morphine plasma concentrations and EEG effects for three different dose levels. Model discrimination was difficult to obtain and selection of the best model (the $\mathrm{EC}_{\mathrm{PL}}$ model in this study) was only possible on basis of the objective function value differences. Moreover, simulations with the $\mathrm{TB}_{\mathrm{PL}}$ model showed that a shift in $\operatorname{Tmax}_{\mathrm{TO}}$ with increasing doses, the distinctive future of the TB model compared to the EC model, only occurs for a limited range in parameter values. Both a $k_{\text {off }}$ value much smaller and much larger than the $k_{e l}$ value and a target concentration larger than the initial drug concentration decrease this shift in $\operatorname{Tmax}_{\mathrm{TO}}$ towards zero.

Since the simulations show that the $\operatorname{Tmax}_{\mathrm{TO}}$ does not depend on the dose for $k_{\text {off }}$ values much lower than the $k_{e l}$ and target concentrations much higher than the initial drug concentration, this means that the $\mathrm{TB}_{\mathrm{PL}}$ model for these parameter values behaves like an $\mathrm{EC}_{\mathrm{PL}}$ model, with a first order increase and decrease in the concentration that is linked to the effect. Together with the small differences in EC and TB model fits to the morphine EEG data, this shows that for many parameter combinations, a TB model

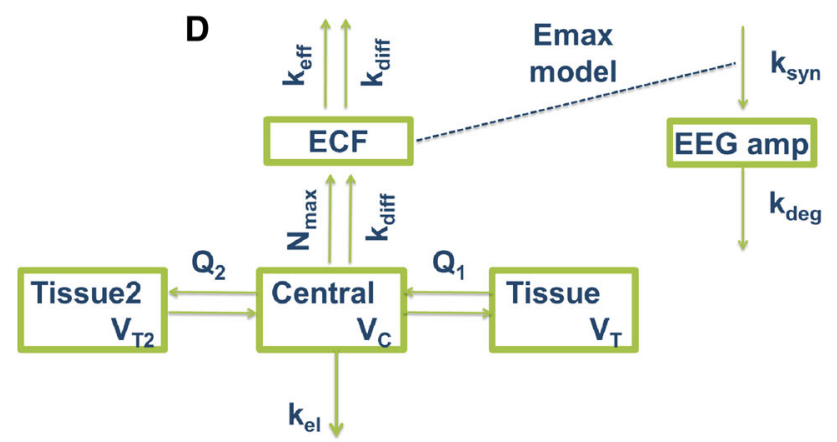

constant, and $k_{\text {deg }}$ being the first-order effect degradation rate constant. The distribution from plasma to the tissue compartments and the brain ECF compartment is described in Supplement S1. The arrows indicate morphine flows, the dotted line indicates a direct relationship

gives rise to similar drug effect profiles as an EC model. This means that neither a successful fit of a TB or EC model necessarily supports the relevance of target binding or target site distribution, respectively, while a single successful fit is often presented as such support $[11,23,39]$. To obtain support for one of the two mechanisms, both models should be fitted to the data and compared on basis of objective metrics such as the AIC. This approach demonstrated the added value of the combined EC- $\mathrm{TB}_{\mathrm{PL}}$ model compared to the $\mathrm{EC}_{\mathrm{PL}}$ and the $\mathrm{TB}_{\mathrm{PL}}$ model for buprenorphine and AR-HO47108 [13, 29]. However, this method also demonstrated that the $\mathrm{TB}_{\mathrm{PL}}$ model performed similarly as the $\mathrm{EC}_{\mathrm{PL}}$ model for eight calcium antagonists [14] and that the EC model performed similarly as the EC-TB ${ }_{\mathrm{PL}}$ model for fentanyl [13]. This demonstrates that even if objective metrics are used, discrimination between two models is not always possible. Moreover, obtained model discrimination strictly informs on the data fit of each model, not directly on the plausibility of the represented mechanism. This lack of discrimination between TB and EC models means that a visually satisfying model fit of the EC model does not indicate that the TB will be not applicable. The TB model should therefore be considered and tested more often as mechanistic 
Table 7 Parameter values and objective function values of the tested models describing the EEG data, based on ECF concentrations

\begin{tabular}{|c|c|c|c|c|c|c|}
\hline & Parameter definition & $\begin{array}{l}\mathrm{EC}_{\mathrm{PL}} 1 \text { ref. } \\
\text { model }\end{array}$ & $\begin{array}{l}\mathrm{TB}_{\mathrm{ECF}} 1 \\
\text { binding model }\end{array}$ & $\begin{array}{l}\mathrm{DE}_{\mathrm{ECF}} 1 \\
\text { direct effect }\end{array}$ & $\begin{array}{l}\mathrm{EC}_{\mathrm{ECF}} 1 \text { effect } \\
\text { compartment }\end{array}$ & $\begin{array}{l}\mathrm{IE}_{\mathrm{ECF}} 1 \\
\text { indirect effect }\end{array}$ \\
\hline OFV & & $25,996.1$ & $26,284.1$ & $26,284.0$ & $26,255.1$ & $26,240.3$ \\
\hline AIC & & $26,118.1$ & $26,300.1$ & $26,300.0$ & $26,273.1$ & $26,258.3$ \\
\hline Parameter & Parameter definition & $\begin{array}{l}\text { Value } \\
(\% \mathrm{CV})\end{array}$ & Value $(\% \mathrm{CV})$ & Value $(\% \mathrm{CV})$ & Value $(\% \mathrm{CV})$ & Value $(\% \mathrm{CV})$ \\
\hline$k_{1 e}(/ \min )$ & Distribution to transit compartment & $0.0457(35)$ & - & - & - & - \\
\hline$k_{e o}(/ \min )$ & Distribution from effect compartment & $0.0377(41)$ & - & - & $0.161(40)$ & - \\
\hline $\begin{array}{l}k_{1 e^{-P g p}(/} \\
\min )\end{array}$ & Distribution to transit with Pgp blocker & $0.0647(36)$ & - & - & - & - \\
\hline $\begin{array}{l}k_{e o}-P g p(/ \\
\min )\end{array}$ & Distribution from effect with Pgp blocker & $0.0155(77)$ & - & - & - & - \\
\hline$E_{0}(\mu \mathrm{V})$ & Baseline EEG amplitude & $47.6(6)$ & $48.9(6)$ & $48.9(6)$ & $49.1(6)$ & $49.1(6)$ \\
\hline$E_{\max }(\mu \mathrm{V})$ & Maximal increase in EEG amplitude & $27.5(20)$ & $32.7(17)$ & $23.4(18)$ & 24.9 (19) & $25.4^{\mathrm{a}}(36)$ \\
\hline $\begin{array}{l}E_{\max }-P g p \\
(\mu \mathrm{V})\end{array}$ & $\begin{array}{l}\text { Maximal increase in EEG amplitude with } \\
\text { Pgp blocker }\end{array}$ & - & & $41.6(14)$ & $43.2(15)$ & $43.3(42)$ \\
\hline $\begin{array}{l}E C_{50} \\
(\mathrm{nM})\end{array}$ & $\begin{array}{l}\text { concentration giving half-maximal } \\
\text { increase in EEG amplitude }\end{array}$ & $1100(87)$ & - & $173(22)$ & $182(26)$ & $182(25)$ \\
\hline$N_{H}$ & Hill factor & $2.05(49)$ & & $2.3(41)$ & $2.02(43)$ & $2.07(43)$ \\
\hline $\begin{array}{l}\text { slope }(\mu \mathrm{V} / \\
\min )\end{array}$ & $\begin{array}{l}\text { Increase in baseline EEG amplitude over } \\
\text { time }\end{array}$ & $\begin{array}{l}-0.0235 \\
(34)\end{array}$ & $-0.0400(17)$ & $\begin{array}{l}-0.0359 \\
(17)\end{array}$ & $-0.0373(19)$ & -0.0377 \\
\hline$k_{\text {off }}(/ \mathrm{min})$ & Dissociation rate constant & - & $0.0932(37)$ & - & - & - \\
\hline$K_{D}$ & Equilibrium constant & - & $283(40)$ & - & - & - \\
\hline$K_{D}-P g p$ & Equilibrium constant with Pgp blocker & - & $55.9(15)$ & - & - & - \\
\hline $\begin{array}{r}k_{d e g}(/ \\
\min )\end{array}$ & Degradation rate constant & & & & & $0.124(34)$ \\
\hline $\begin{array}{c}\omega^{2} E_{0} \\
(\mu \mathrm{V})\end{array}$ & Variance of IIV on $E_{0}$ & 0.0668 & $0.0668(26)$ & $0.072(25)$ & $0.0696(26)$ & $0.0961(26)$ \\
\hline$\sigma^{2}$ prop & Variance of proportional error & $0.0550(10)$ & $0.0598(10)$ & $0.0598(10)$ & $0.0593(10)$ & $0.059(10)$ \\
\hline
\end{tabular}

${ }^{a}$ This value was estimated as the maximal $k_{s y n}$ minus baseline $k_{s y n}$ (calculated from $E_{0}$ and $k_{d e g}$ ) and calculated by dividing the estimated value by the $k_{\text {deg }}$

alternative to the EC model to find the best fitting model. Moreover, the TB model parameters can be measured partially in vitro/ex vivo, which enables a better in vitroin vivo extrapolation (IVIVE).

In this study, the models based on brain ECF concentrations did not perform better than the models based on plasma concentrations. One would expect that the brain ECF concentrations would reflect the target site concentration better than the plasma concentrations, especially if brain distribution is relatively slow and nonlinear, as it was in this study. The inferior performance of the brain ECFbased models might be explained by the extremely high variability in the brain ECF data of the $4 \mathrm{mg} / \mathrm{kg}$ dose group, as shown in Figure S5. However, a direct effect model $\left(\mathrm{DE}_{\mathrm{ECF}} 1\right)$ could be identified from the brain ECF concentrations and showed an only 39 points higher AIC than the best model $\mathrm{IE}_{\mathrm{ECF}} 1$, while an IE model fit could not be obtained from the plasma concentrations, indicating that the ECF concentrations reflect the target site concentration more closely compared to the plasma concentrations. This is in line with the relevance of drug concentrations in the brain for CNS effects that has been demonstrated by several other studies [40-43] and the difference between plasma and brain concentrations that has been identified for several compounds [44]. In all our target binding models, a linear target occupancy-effect relationship had to be assumed to keep the model parameters identifiable. Such a linear relationship has been observed and can be expected unless for full agonists in tissues with relatively high target concentrations compared to the concentration of signal transduction molecules (i.e. for a high receptor reserve) [24].

Only a one compartment pharmacokinetic model was used in this study in combination with the simplest $\mathrm{TB}_{\mathrm{PL}}$ model to investigate the $\Delta \operatorname{Tmax}_{\mathrm{TO}}$. The same principles are expected to apply if the $\mathrm{TB}_{\mathrm{PL}}$ model has a two-compartment or three-compartment pharmacokinetic model or with target turnover and signal transduction models, but the 


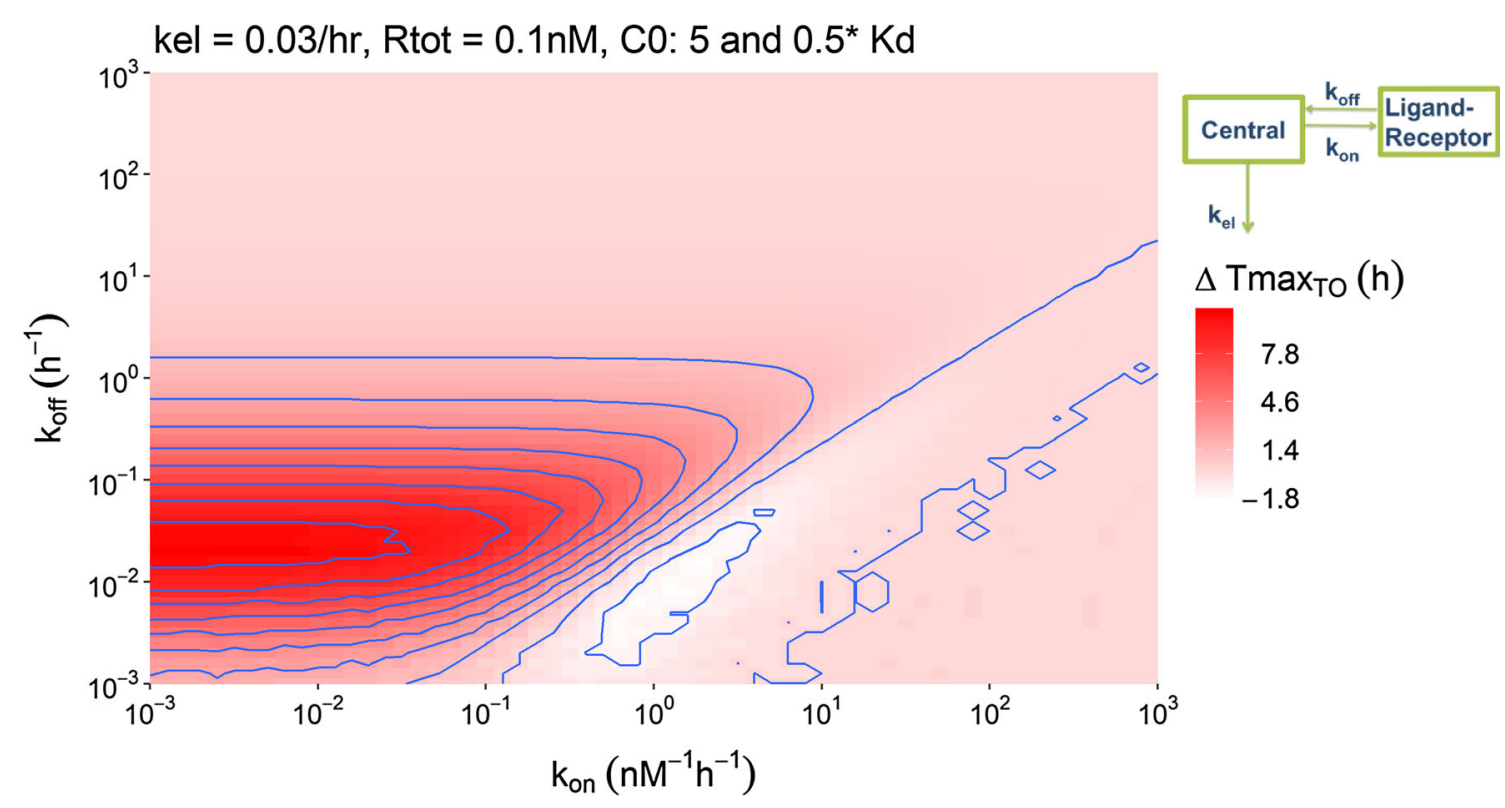

Fig. 5 Overview of the shift in $\operatorname{Tmax}_{\mathrm{TO}}$ that was observed in the simulations with the $\mathrm{TB}_{\mathrm{PL}}$ model (see upper-right corner), as a result of the change in the affinity-normalized dose (leading to an initial concentration of 5 and 0.5 times the $K_{D}$ ). Each pixel represents a single simulation in which the $k_{\text {off }}$ and $k_{\text {on }}$ value correspond to the

position on the $y$-axis and the $\mathrm{x}$-axis, respectively, and the color represents the observed shift in $\mathrm{Tmax}_{\mathrm{TO}}$ in that simulation. The elimination rate constant $k_{e l}$ was $0.03 / \mathrm{hr}$ and the target concentration was $0.1 \mathrm{nM}$ for all simulations in this figure

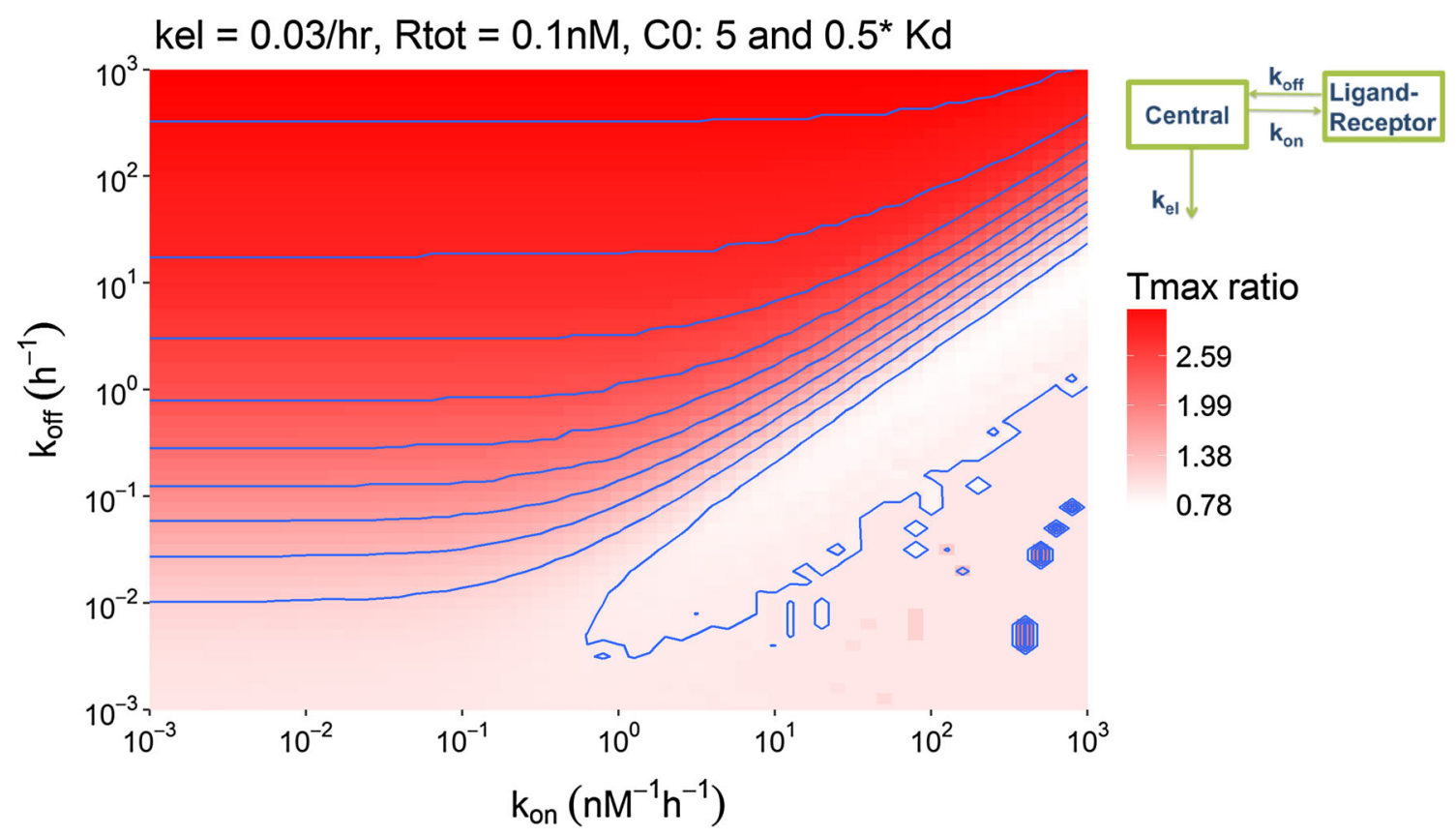

Fig. 6 Overview of the ratio of $\operatorname{Tmax}_{\mathrm{TO}}$ values that was observed in the simulations with the $\mathrm{TB}_{\mathrm{PL}}$ model (see inset) as a result of the change in the affinity-normalized dose (leading to an initial concentration of 5 and 0.5 times the $K_{D}$ ). Each pixel represents a single simulation in which the $k_{\text {off }}$ and $k_{\text {on }}$ value correspond to the position

parameter range for which $\operatorname{Tmax}_{\mathrm{TO}}$ shifts with a change in dose might be different compared to the model used in the simulations. In analogy to Fig. 7, for the combined EC-TB on the $\mathrm{y}$-axis and the $\mathrm{x}$-axis, respectively, and the color represents the observed shift in $\operatorname{Tmax}_{\mathrm{TO}}$ in that simulation. The elimination rate constant $k_{e l}$ was $0.03 / \mathrm{hr}$ and the target concentration was $0.1 \mathrm{nM}$ for all simulations in this figure

model one would expect that to obtain a significant $\Delta \mathrm{Tmax}_{\mathrm{TO}}$ and to identify the TB model in addition to the EC model, the $k_{e 0}$ should be in the same order of 


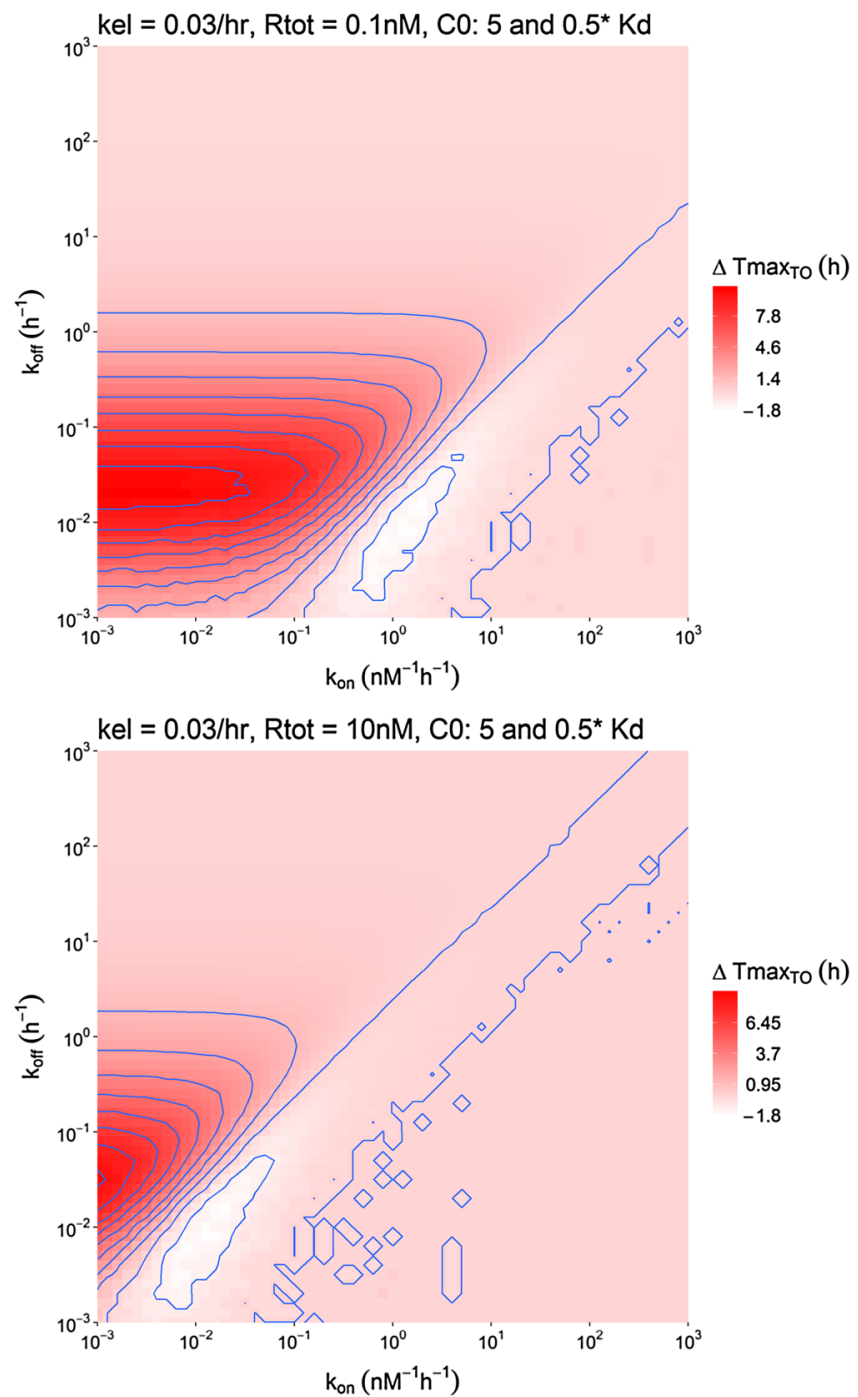

Fig. 7 Overview of the $\Delta \operatorname{Tmax}_{\mathrm{TO}}$ that was observed in the simulations as a result of the change in the affinity-normalized dose for different combinations of parameter values as indicated above the panels. Each pixel represents a single simulation in which the $k_{\text {off }}$ and

magnitude as the $k_{\text {off }}$ if the maximal drug concentration is around or below the $K_{D}$. This is indeed the case for the two successful examples of an EC-TB ${ }_{\mathrm{PL}}$ fit: for buprenorphine, the $k_{e 0}$ was $0.0242 / \mathrm{min}$ and the $k_{\text {off }}$ was $0.0731 / \mathrm{min}$ [13] and for AR-HO47108, the $k_{e 0}$ was 0.0351 for the drug and 0.00749 for its metabolite and the $k_{\text {off }}$ was 0.00303 and $0.00827 / \mathrm{min}$, respectively [29]. On the other hand, the combined EC-TB model EC-TB $\mathrm{PL}_{1} 1$ that was identified in this study for morphine also showed a similar value for $k_{e 0}$ and $k_{\text {off }}(0.0327$ and 0.275 , respectively), but this model was not better than the EC model $\mathrm{EC}_{\mathrm{PL}} 1$. In comparison with our one compartment pharmacokinetics model with intravenous dosing, especially the absorption or the distribution phase into the target site could pose additional

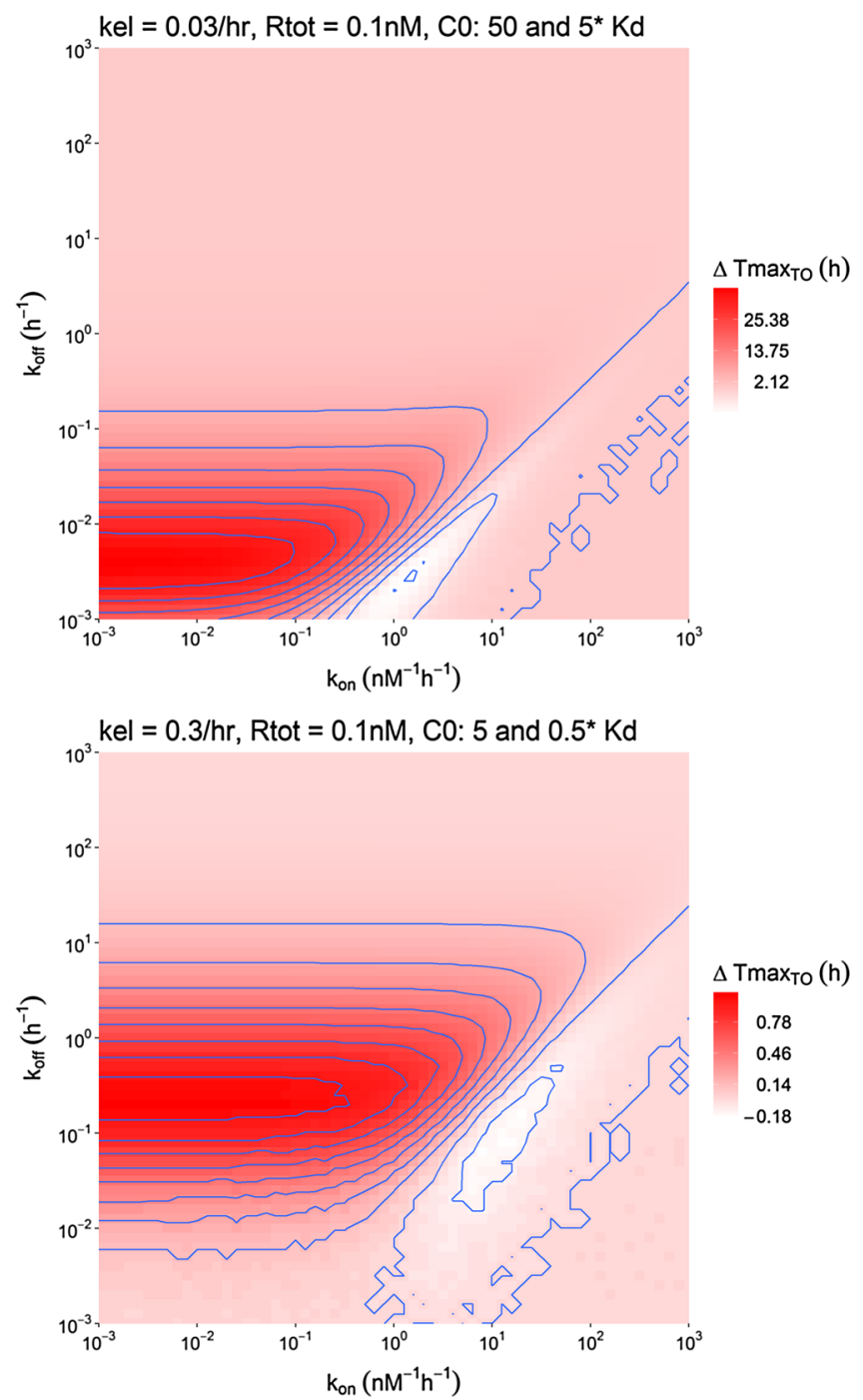

$k_{\text {on }}$ value correspond to the position on the $\mathrm{y}$-axis and the $\mathrm{x}$-axis, respectively, and the color represents the observed shift in $\operatorname{Tmax}_{\mathrm{TO}}$ in that simulation. All panels vary only one other parameter compared to the upper left panel

limiting factors that prevent a shift in $\operatorname{Tmax}_{\mathrm{TO}}$ with increasing doses.

One of the most important advantages of the EC model is that it only requires one parameter, $k_{e 0}$. However, the EC model most often needs to be combined with an Emax model, which also requires two or three parameters, Emax, $E C_{50}$ and possibly the hill factor. The binding model has three parameters, $k_{o n}, k_{\text {off }}$ and $R_{t o t}$, and needs at least 1 additional parameter, Emax, to convert occupancy predictions to effect predictions. One or two additional parameters might be required to describe a nonlinear target occupancy-effect relationship, which is required in case of a high efficacy and receptor reserve [24]. The discrimination between the two nonlinearities in such cases might be hard or impossible to obtain. However, $k_{\text {on }}$ and $k_{\text {off }}$ can be 
obtained from in vitro experiments and $R_{\text {tot }}$ from ex vivo experiments. Especially the identification of $R_{t o t}$ from ex vivo data can help to reduce the difficulties with parameter identifiability as often associated with the TB model [45]. It should be noted that the measurement of in vitro target binding only helps to explain/describe the delay between pharmacokinetics and pharmacodynamics if the target binding kinetics are the rate-limiting step in this delay in vivo. As biologics often display lower dissociation rate-constants and their target binding is more often affecting the pharmacokinetics compared to small molecules, as exemplified by the multitude of TMDD model applications in this area, one could expect that the TB model is mostly relevant for biologics. However, small molecules can also have low dissociation rate-constants, as exemplified by the irreversible binders aspirin and omeprazole and the target association-dissociation of the semi-synthetic opioid buprenorphine. Moreover, the increasing interest in the pharmaceutical industry to design small molecules with low dissociation rate-constants can lead to an increase in the number of such molecules in drug discovery and development and the associated modeling efforts.

In summary, the limited difference between TB and EC models should be taken into account in the evaluation of historical and the design of new modelling studies. By informing the TB models with in vitro data, TB models can help to translate between in vitro and in vivo studies if the target binding is a rate-limiting step. The combination of parameter values for which the $\operatorname{Tmax}_{\mathrm{TO}}$ in the target binding model is dependent on the dose is limited to $k_{\text {off }}$ values around the elimination rate constant and to target concentrations lower than the initial drug concentration. Although the combination of multi-compartment pharmacokinetics models, TB models and target turnover models might affect the parameter range were the $\operatorname{Tmax}_{\mathrm{TO}}$ is dependent on the dose, this study is a first indication that such limitations should be taken into account for understanding TB models.

\section{Conclusion}

In this study, it was shown that successful fitting of a TB or EC model is not enough support to assume the relevance of target binding or target site distribution. Moreover, for a one-compartment pharmacokinetic model with target binding, the $\Delta \operatorname{Tmax}_{\mathrm{TO}}$ for changing doses can only be identified if the $k_{\text {off }}$ has a value around the pharmacokinetic elimination rate constant and the target concentration is lower than the initial drug concentration. The $\operatorname{Tmax}_{\mathrm{TO}}$ is determined by the rate of target binding relative to the decline rate of unbound drug and unbound target concentrations. These findings indicate that the relatively sparse occurrence of target binding models in literature does not discredit the relevance of target binding kinetics. This study also shows that a TB and EC model might be similar for the tested dose range and pharmacokinetic conditions, while extrapolation to different conditions might result in different effect versus time profiles for the $\mathrm{TB}$ and EC model. In conclusion, the identification of the appropriate model is important and target binding models should be tested more often to increase the translation between in vitro and in vivo studies and to increase the predictive power of developed PKPD models.

Acknowledgements This research is part of the K4DD (Kinetics for Drug Discovery) consortium which is supported by the Innovative Medicines Initiative Joint Undertaking (IMI JU) under grant agreement no 115366 . The IMI JU is a project supported by the European Union's Seventh Framework Programme (FP7/2007-2013) and the European Federation of Pharmaceutical Industries and Associations (EFPIA).

Open Access This article is distributed under the terms of the Creative Commons Attribution 4.0 International License (http://creative commons.org/licenses/by/4.0/), which permits unrestricted use, distribution, and reproduction in any medium, provided you give appropriate credit to the original author(s) and the source, provide a link to the Creative Commons license, and indicate if changes were made.

\section{References}

1. Copeland RA, Pompliano DL, Meek TD (2006) Drug-target residence time and its implications for lead optimization. Nat Rev Drug Discov 5:730-739. https://doi.org/10.1038/nrd2082

2. Lu H, Tonge PJ (2011) Drug-target residence time: critical information for lead optimization. Curr Opin Chem Biol 14:467-474. https://doi.org/10.1016/j.cbpa.2010.06.176.DrugTarget

3. Dahl G, Akerud T (2013) Pharmacokinetics and the drug-target residence time concept. Drug Discov Today 18:697-707

4. Schuetz DA, de Witte WEA, Wong YC, Knasmueller B, Richter L, Kokh DB, Sadiq SK, Bosma R, Nederpelt I, Heitman LH, Segala E, Amaral M, Guo D, Andres D, Georgi V, Stoddart LA, Hill S, Cooke RM, De Graaf C, Leurs R, Frech M, Wade RC, de Lange ECM, Ijzerman AP, Müller-Fahrnow A, Ecker GF (2017) Kinetics for drug discovery: an industry-driven effort to target drug residence time. Drug Discov Today 22:896-911. https://doi. org/10.1016/j.drudis.2017.02.002

5. de Witte WEA, Wong YC, Nederpelt I, Heitman LH, Danhof M, van der Graaf PH, Gilissen RA, de Lange EC (2016) Mechanistic models enable the rational use of in vitro drug-target binding kinetics for better drug effects in patients. Expert Opin Drug Discov 11:45-63. https://doi.org/10.1517/17460441.2016. 1100163

6. de Witte WEA, Danhof M, van der Graaf PH, de Lange ECM (2016) In vivo target residence time and kinetic selectivity: the association rate constant as determinant. Trends Pharmacol Sci 37:831-842. https://doi.org/10.1016/j.tips.2016.06.008

7. Vauquelin G, Bostoen S, Vanderheyden P, Seeman P (2012) Clozapine, atypical antipsychotics, and the benefits of fast-off D2 dopamine receptor antagonism. Naunyn Schmiedebergs Arch 
Pharmacol 385:337-372. https://doi.org/10.1007/s00210-0120734-2

8. Sahlholm K, Zeberg H, Nilsson J, Ögren SO, Fuxe K, Århem P (2016) The fast-off hypothesis revisited: a functional kinetic study of antipsychotic antagonism of the dopamine D2 receptor. Eur Neuropsychopharmacol 26:467-476. https://doi.org/10.1016/ j.euroneuro.2016.01.001

9. Ramsey SJ, Attkins NJ, Fish R, van der Graaf PH (2011) Quantitative pharmacological analysis of antagonist binding kinetics at CRF1 receptors in vitro and in vivo. Br J Pharmacol 164:992-1007. https://doi.org/10.1111/j.1476-5381.2011.01390.x

10. Jiang XL, Samant S, Lewis JP, Horenstein RB, Shuldiner AR, Yerges-Armstrong LM, Peletier LA, Lesko LJ, Schmidt S (2016) Development of a physiology-directed population pharmacokinetic and pharmacodynamic model for characterizing the impact of genetic and demographic factors on clopidogrel response in healthy adults. Eur J Pharm Sci 82:64-78. https://doi.org/10. 1016/j.ejps.2015.10.024

11. Hong Y, Gengo FM, Rainka MM, Bates VE, Mager DE (2008) Population pharmacodynamic modelling of aspirin- and ibuprofen-induced inhibition of platelet aggregation in healthy subjects. Clin Pharmacokinet 47:129-137. https://doi.org/10.2165/ 00003088-200847020-00006

12. Äbelö A, Holstein B, Eriksson UG, Gabrielsson J, Karlsson MO (2002) Gastric acid secretion in the dog: a mechanism-based pharmacodynamic model for histamine stimulation and irreversible inhibition by omeprazole. J Pharmacokinet Pharmacodyn 29:365-382. https://doi.org/10.1023/A:1020905224001

13. Yassen A, Olofsen E, Dahan A, Danhof M (2005) pharmacokinetic-pharmacodynamic modeling of the antinociceptive effect of buprenorphine and fentanyl in rats: role of receptor equilibration kinetics. J Pharmacol Exp Ther 313:1136-1149. https://doi.org/ 10.1124/jpet.104.082560.response

14. Shimada S, Nakajima Y, Yamamoto K, Sawada Y, Iga T (1996) Comparative pharmacodynamics of eight calcium channel blocking agents in Japanese essential hypertensive patients. Biol Pharm Bull 19:430-437

15. Dua P, Hawkins E, van der Graaf P (2015) A tutorial on targetmediated drug disposition (TMDD) models. CPT Pharmacometrics Syst Pharmacol 4:324-337. https://doi.org/10.1002/psp4.41

16. Lammertsma AA, Hume SP (1996) Simplified reference tissue model for PET receptor studies. Neuroimage 4:153-158. https:// doi.org/10.1006/nimg.1996.0066

17. Liefaard LC, Ploeger BA, Molthoff CFM, Boellaard R, Lammertsma AA, Danhof M, Voskuyl RA (2005) Population pharmacokinetic analysis for simultaneous determination of Bmax and $\mathrm{KD}$ in vivo by positron emission tomography. Mol imaging Biol 7:411-421. https://doi.org/10.1007/s11307-005-0022-3

18. Louizos C, Yáñez JA, Forrest ML, Davies NM (2014) Understanding the hysteresis loop conundrum in pharmacokinetic/ pharmacodynamic relationships. J Pharm Pharm Sci 17:34-91

19. Upton R, Mould D (2014) Basic concepts in population modeling, simulation, and model-based drug development: Part 3Introduction to pharmacodynamic modeling methods. CPT Pharmacometrics Syst Pharmacol. https://doi.org/10.1038/psp. 2013.71

20. Holford NHG, Sheiner LB (1981) Understanding the dose-effect relationship: clinical application of pharmacokinetic-pharmacodynamic models. Clin Pharmacokinet 6:429-453

21. Jusko WJ, Ko HC (1994) Physiologic indirect response models characterize diverse types of pharmacodynamic effects. Clin Pharmacol Ther 56:406-419. https://doi.org/10.1038/clpt.1994. 155

22. Paton WDM (1961) A theory of drug action based on the rate of drug-receptor combination. Proc R Soc Lond B 154:21-69. https://doi.org/10.1086/303379
23. Perry DC, Mullis KB, Oie S, Sadée W (1980) Opiate antagonist receptor binding in vivo: evidence for a new receptor binding model. Brain Res 199:49-61

24. Ruffolo RR (1982) Important concepts of receptor theory. J Auton Pharmacol 2:277-295. https://doi.org/10.1111/j.1474-8673. 1982.tb00520.x

25. Wakelkamp M, Alván G, Paintaud G (1998) The time of maximum effect for model selection in pharmacokinetic-pharmacodynamic analysis applied to frusemide. $\mathrm{Br} \mathrm{J}$ Clin Pharmacol 45:63-70

26. Ploeger BA, Van Der Graaf PH, Danhof M (2009) Incorporating receptor theory in mechanism-based pharmacokinetic-pharmacodynamic (PK-PD) modeling. Drug Metab Pharmacokinet 24:3-15

27. Dayneka NL, Garg V, Jusko WJ (1993) Comparison of four basic models of indirect pharmacodynamic responses. J Pharmacokinet Biopharm 21:457-477. https://doi.org/10.1007/BF01061691

28. Peletier LA, Gabrielsson J, Den Haag J (2005) A dynamical systems analysis of the indirect response model with special emphasis on time to peak response. J Pharmacokinet Pharmacodyn 32:607-654. https://doi.org/10.1007/s10928-005-0047-x

29. Äbelö A, Andersson M, Holmberg AA, Karlsson MO (2006) Application of a combined effect compartment and binding model for gastric acid inhibition of AR-HO47108: a potassium competitive acid blocker, and its active metabolite AR-HO47116 in the dog. Eur J Pharm Sci 29:91-101

30. Yassen A, Olofsen E, Kan J, Dahan A, Danhof M (2007) Animalto-human extrapolation of the pharmacokinetic and pharmacodynamic properties of buprenorphine. Clin Pharmacokinet 46:433-447

31. Cleton A, de Greef HJ, Edelbroek PM, Voskuyl RA, Danhof M (1999) Application of a combined "effect compartment/indirect response model" to the central nervous system effects of tiagabine in the rat. J Pharmacokinet Biopharm 27:301-323

32. Jusko WJ, Ko HC, Ebling WF (1995) Convergence of direct and indirect pharmacodynamic response models. J Pharmacokinet Biopharm 23:5-8. https://doi.org/10.1007/BF02353781

33. Hutmacher MM, Mukherjee D, Kowalski KG, Jordan DC (2005) Collapsing mechanistic models: an application to dose selection for proof of concept of a selective irreversible antagonist. J Pharmacokinet Pharmacodyn 32:501-520. https://doi.org/10. 1007/s10928-005-0052-0

34. Groenendaal D, Freijer J, de Mik D, Bouw MR, Danhof M, de Lange EC (2007) Influence of biophase distribution and P-glycoprotein interaction on pharmacokinetic-pharmacodynamic modelling of the effects of morphine on the EEG. Br J Pharmacol 151:713-720. https://doi.org/10.1038/sj.bjp.0707258

35. Groenendaal D, Freijer J, de Mik D, Bouw MR, Danhof M, de Lange EC (2007) Population pharmacokinetic modelling of nonlinear brain distribution of morphine: influence of active saturable influx and P-glycoprotein mediated efflux. $\mathrm{Br} \mathrm{J}$ Pharmacol 151:701-712. https://doi.org/10.1038/sj.bjp.0707257

36. Beal S, Sheiner LB, Boeckmann A, Bauer RJ (1989-2013) NONMEM 7.3.0 users guides. Icon Development Solutions, Hanover

37. Akaike H (1992) Information theory and an extension of the maximum likelihood principle. In: Kotz S, Johnson NL (eds) Breakthroughs in statistics. Foundations and basic theory, vol 1. Springer, New York, pp 610-624

38. Zhang L, Beal SL, Sheiner LB (2003) Simultaneous vs. sequential analysis for population PK/PD data I: best-case Performance. J Pharmacokinet Pharmacodyn 30:387-404. https:// doi.org/10.1023/B:JOPA.0000012999.36063.4e

39. Walkup GK, You Z, Ross PL, Allen EK, Daryaee F, Hale MR, O'Donnell J, Ehmann DE, Schuck VJ, Buurman ET, Choy AL, Hajec L, Murphy-Benenato K, Marone V, Patey SA, Grosser LA, 
Johnstone M, Walker SG, Tonge PJ, Fisher SL (2015) Translating slow-binding inhibition kinetics into cellular and in vivo effects. Nat Chem Biol 11:416-423. https://doi.org/10.1038/nchembio. 1796

40. Stevens J, Ploeger BA, Hammarlund-Udenaes M, Osswald G, van der Graaf PH, Danhof M, de Lange EC (2012) Mechanism-based PK-PD model for the prolactin biological system response following an acute dopamine inhibition challenge: quantitative extrapolation to humans. J Pharmacokinet Pharmacodyn 39:463-477. https://doi.org/10.1007/s10928-012-9262-4

41. Larsen MS, Keizer R, Munro G, Mørk A, Holm R, Savic R, Kreilgaard M (2016) Pharmacokinetic/pharmacodynamic relationship of gabapentin in a CFA-induced inflammatory hyperalgesia rat model. Pharm Res 33:1133-1143. https://doi.org/10. 1007/s11095-016-1859-7

42. Danhof M, Levy G (1984) Kinetics of drug action in disease states. I. Effect of infusion rate on phenobarbital concentrations in serum, brain and cerebrospinal fluid of normal rats at onset of loss of righting reflex1. J Pharmacol Exp Ther 229:44-50

43. Balerio GN, Rubio MC (2002) Pharmacokinetic-pharmacodynamic modeling of the antinociceptive effect of baclofen in mice. Eur J Drug Metab Pharmacokinet 27:163-169

44. Yamamoto Y, Välitalo PA, van den Berg D-J, Hartman R, van den Brink W, Wong YC, Huntjens DR, Proost JH, Vermeulen A, Krauwinkel W, Bakshi S, Aranzana-Climent V, Marchand S, Dahyot-Fizelier C, Couet W, Danhof M, van Hasselt JGC, de Lange ECM (2017) A generic multi-compartmental CNS distribution model structure for 9 drugs allows prediction of human brain target site concentrations. Pharm Res 34:333-351. https:// doi.org/10.1007/s11095-016-2065-3

45. Janzén DLI, Bergenholm L, Jirstrand M, Parkinson J, Yates J, Evans ND, Chappell MJ (2016) Parameter identifiability of fundamental pharmacodynamic models. Front Physiol 7:1-12. https://doi.org/10.3389/fphys.2016.00590 